\title{
La elección popular de los jueces de paz en la provincia de Buenos Aires. Fracaso y conflicto de poderes
}

\author{
Por María Angélica Corva
}

\section{Introducción}

En su libro sobre la doctrina de la separación de poderes, Maurice Vile realizó un pormenorizado análisis de una corriente de pensamiento constitucional que intentaba equilibrar la libertad de los ciudadanos con el ejercicio del poder estatal. Al exponer el pensamiento de Thomas Jefferson, explicaba que según su defensa del sistema de frenos y contrapesos el único correctivo eficaz contra los abusos de poder era el poder de los electores, aplicado a los tres departamentos del Estado, legislativo, ejecutivo y judicial, cuyos miembros debían ser elegidos por votación de periodicidad frecuente. Uno de los más prominentes jeffersonianos, John Taylor, fue más lejos sosteniendo que la manera más adecuada de elevar al Poder Judicial a la categoría de rama del Estado, acorde al principios de división que ellos sostenían, era hacer que sus miembros lo fueran por cargos electos, de modo que tuvieran que rendir cuentas ante al pueblo (Vile, 2007: 185-191).

En el Río de la Plata, el profesor de derecho constitucional Florentino González enseñaba en sus lecciones que el ejercicio de las funciones de poder debía estar distribuido, para que no fuesen los mismos quienes hiciesen, ejecutasen y aplicasen la ley. Eso se lograba con la división del ejercicio de las funciones del poder en varios departamentos, "cuyos miembros se sirven recíprocamente de contrapeso para contener los excesos, y de apoyo al ciudadano para usar con seguridad de sus libertades y derechos". Constituir un gobierno era concretar esa división, estableciendo las relaciones entre los funcionarios de cada departamento, asegurándoles independencia de acción dentro de la esfera de sus respectivas facultades, haciéndolos al mismo tiempo responsable de sus abusos de autoridad, permitiendo el control a los ciudadanos (González, 1869: 172-184). ${ }^{1}$

Estas ideas estuvieron presentes en las sesiones para la redacción de la Constitución de la provincia de Buenos Aires de 1873, donde la forma de elección de los jueces letrados fue uno de los temas que generó mayor debate - durante tres largas sesiones - y de los que sufrió un cambio más abrupto entre el proyecto original y el artículo finalmente sancionado, según el cual eran elegidos por el

1 En 1868 se creó la cátedra de Derecho Constitucional y Administrativo del Departamento de Jurisprudencia de la Universidad de Buenos Aires, a cargo de Florentino González, emigrado colombiano que llegó desde Chile y escribió las Lecciones de derecho constitucional. 
Poder Ejecutivo con acuerdo del Senado y no en forma directa por el pueblo (Corva, 2014: 232-236). El enfrentamiento generado en los debates planteaba dos opciones para la elección de los magistrados letrados del poder encargado de administrar justicia: por los otros poderes públicos o directamente por el pueblo.

La respuesta a esta cuestión tenía su fundamento en el concepto de soberanía y de su ejercicio, aunque se le quisiera dar a la opción por la elección en segundo grado un perfil práctico, basado en la falta de capacidad del pueblo elector para discernir sobre la idoneidad, inteligencia y honorabilidad de los jueces. Ambas posturas buscaban responder a la garantía de justicia, pero siempre relacionada con la responsabilidad del magistrado al ejercer su función. En la primera opción haciendo que ese acto fuera realizado por quienes tuvieran aptitud para ejercerlo; en la segunda haciendo uso de la libertad de la sociedad civil para elegir quién administraba justicia. ${ }^{2}$

Respecto a los jueces de paz, la cuestión estaba más ligada a la descentralización por todos aceptada y por esto la elección popular tuvo escasa oposición y fue incorporada en el texto constitucional. Pero la ley que debía instrumentarla fracasó y la frustración de la elección directa tal vez se debió a que daría por tierra con un importante recurso de poder del Ejecutivo. Pero también representaba el enfrentamiento entre el Poder Ejecutivo y el Poder Legislativo, que se manifestó en la discusión sobre la forma alternativa de elección a la que se recurriría hasta que la Justicia de Paz tuviera su ley orgánica. ${ }^{3}$

El conflicto nacía de la naturaleza doble y ambigua del sistema municipal en Hispanoamérica, que generó una tensión entre la representación de los intereses locales y la subordinación al poder central, y que no fue eliminada de un plumazo con la modernidad política y el constitucionalismo. El gobierno buscaba en el municipio un órgano administrativo y los vecinos un instrumento de autogobierno local. A esto se sumaba la falta de una división entre la justicia y la administración, que no lograba realizarse a pesar de los esfuerzos constitucionales (Morelli, 2007: 116-129). Para comprender los orígenes de la separación entre función judicial y función administrativa, es primordial no dar por hecha la teoría de los tres poderes del Estado, en que legislación, jurisdicción y administración se presentan como "funciones necesarias y naturales" de cada Estado (Mannori, 2007: 125-146). Esto es especialmente visible en la justicia de la provincia de Buenos Aires durante el siglo XIX y en la definición de la forma de elección de sus jueces.

El proceso político en el Río de la Plata hasta 1852 estuvo caracterizado por la concentración de poderes, que tuvo su base en la pervivencia de la Real Ordenanza de Intendentes de 1782, ordenamiento político y administrativo del Virreinato

2 Debates de la Convención Constituyente de Buenos Aires, 1870-1873. Publicación Oficial hecha bajo la dirección del convencional Luis V. Varela, reimpresión con índice alfabético y cronológico confeccionado por Adrián Becar Varela, La Plata, Taller de Impresiones Oficiales, 1920 (en adelante DCC) La elección de los jueces letrados se trató en las sesiones del 19, 21 y 26 de marzo de 1873.

3 Sesión del 27 de junio de 1873, DCC. 
rioplatense que prolongó su influencia y dejó sus sedimentos en las nuevas organizaciones institucionales. Las reformas eran parciales y la división de poderes, enunciada desde el Reglamento dado por la Junta Conservadora el 22 de octubre de 1811, tardó muchos años en concretarse, especialmente en lo referido a la formación de un poder judicial independiente (Cansanello, 2003: cap. V; Levaggi: 1981, 284).

En la provincia de Buenos Aires, la dificultad de separar administración y justicia se hacía visible en los jueces de paz de los partidos, cuyo nombramiento tenía estrecha relación con la burocracia local, una forma de estructuración social que ritualizaba conductas y comportamientos de acuerdo a códigos compartidos a los que la sociedad debía adecuarse en relación con la propiedad de la tierra, la consolidación de los pueblos y la expansión de la frontera. (Garavaglia, 2007: 228230) Por esto, es importante reconstruir el perfil de los sujetos que ejercieron el cargo de jueces de paz, para entender las lógicas que guiaron su designación y observar la dinámica y funcionamiento de la institución. Establecidas esas lógicas de designación, ha podido dilucidarse que fueron mudando en función al contexto y la situación de la ocupación del territorio (Di Gresia, 2010: 1-3).

Pero tan importante como saber quiénes eran y cómo actuaban, es saber quién y cómo los elegía y los nombraba. La Constitución de 1873 buscaba la descentralización, separando las funciones judiciales y administrativas, logrando que la división de poderes republicana superara la teoría y se concretara a nivel local con municipalidades y una organización judicial cercana y accesible, para que el litigio se resolviera allí donde se producía. El juez de paz debía convertirse en la base del sistema judicial provincial y para ello era indispensable organizar un sistema municipal a cargo de jurisdicciones locales. Pensado así, el texto constitucional estableció que los jueces de paz fueran funcionarios exclusivamente judiciales y agentes de los tribunales de justicia - es decir que ya no eran presidentes de las municipalidades de la campaña - siendo electos directamente por electores calificados. La forma y tiempo de elección, así como la duración en funciones, debía ser establecida por una ley que fue promulgada el 23 de mayo de 1878, pero cuyos efectos fueron suspendidos -junto con los de la ley de Municipalidades- el 4 de septiembre, así como las elecciones de municipales y jueces de paz programadas.

Es nuestro objetivo conocer el contenido de esa ley de organización de la Justicia de Paz, en especial en lo referente a la elección popular, para luego analizar el conflicto de poderes que se produjo en relación a su concreción y el papel que la Suprema Corte de Justicia jugó en su resolución. Como paso previo, realizaremos una pesquisa en la legislación anterior (incluida la Constitución del Estado de Buenos Aires de 1854) sobre las funciones y mecanismos de nombramiento de los jueces de paz, desde su creación en 1821. Para toda esta tarea recurrimos a la Convención Constituyente de 1870-1873, a los Registros Oficiales provinciales, a las notas del juzgado de paz de Exaltación de la Cruz (partido de la provincia) y fundamentalmente al expediente de la Suprema Corte, que expone las posturas de 
cada poder y contiene como antecedentes los debates legislativos relacionados con la ley de elección de los jueces de paz.

\section{La Justicia de Paz hasta la Constitución de 1873}

En la provincia de Buenos Aires, la ley promovida por Rivadavia en 1821 suprimió los Cabildos hasta que se creyera oportuno "establecer la ley general de Municipalidades", quedando en cada parroquia un juez de paz, que en la campaña, a más de sus atribuciones judiciales, reunía las de los suprimidos alcaldes de hermandad incluyendo funciones administrativas y de policía (Díaz, 1859: 9; Romay, 1950: 108-138). La justicia ordinaria era administrada por cinco jueces de primera instancia letrados, rentados e inamovibles, dos en la ciudad y tres en a campaña. ${ }^{4}$ El nombramiento del juez de paz en la campaña siguió determinando la formación de un partido, como lo hiciera el del alcalde de hermandad antes de 1821 (Levene, 1940: 115-117). Se buscaba así una solución que combinaba en los espacios locales nociones modernas de representación política, centralización y división de funciones en los partidos, una jurisdicción de tradición hispánica, como lo eran también las atribuciones de los alcaldes de hermandad que se prolongaban en los jueces de paz (Ternavasio, 199: 22). Para Carlos Heras, la Real Ordenanza de Intendentes fue el comienzo de la decadencia de los Cabildos, su golpe de muerte y un avasallamiento a las ciudades. (Heras, 1925: 445-485).

El juez de paz concentró funciones militares, electorales, de escribano y agente del Ejecutivo, pero también su competencia judicial fue ampliada. Originariamente juzgaba en todas las demandas que las leyes y prácticas declaraban verbales y arbitraba en las diferencias, pero sus funciones judiciales se consolidaron con el fracaso de la instalación de la justicia letrada y la organización policial en la campaña. Los jueces de primera instancia de la campaña fueron eliminados entre 1824 y 1853 (Díaz, 1859: 98-99; Fradkin, 2009: 143-164).

Los jueces de paz eran vecinos legos, es decir sin formación profesional, que el gobierno intentó suplir con manuales, como el redactado por Manuel García en 1825. ${ }^{5} \mathrm{Su}$ texto establecía la jurisdicción civil, criminal $^{6}$ y las funciones de los

4 Registro Oficial de la Provincia de Buenos Aires (en adelante ROPBA), 1821-1825, pp. 124 125. La ley organizaba también la policía (con la inspección de mercados y abastos en toda la provincia) que quedaban a cargo de un jefe de policía, con seis comisarios para la capital y ocho para la campaña. En febrero de 1825 se restablecieron los cargos de comisarios de policía de campaña que habían sido suspendidos en noviembre del año anterior, asumiendo sus funciones los jueces de paz. Lo mismo sucedió con un decreto del 25 de enero de 1830 que restablecía los comisarios de campaña, eliminados del presupuesto. Pero en 1831, el juez de paz asumió las funciones policiales y el 17 de febrero el Gobierno acordó que los jueces de paz cobraran el salario por sus funciones de comisario. A pesar de algunos cambios, esta situación no terminó de definirse hasta la creación de la Policía de la Provincia en 1880.

5 Manual para los jueces de paz de campaña, Buenos Aires, Imprenta de la Independencia, 1825. 
jueces de paz en la campaña en delitos graves como sumariantes. En el manual el juez podía consultar los formularios de los trámites que realizar en cumplimiento de sus atribuciones y el texto de las leyes necesarias (Corva, 2001). El procedimiento en las causas en que dictaba sentencia era verbal, con dos testigos, debiendo constar en el libro de actas la demanda, contestación, prueba y resolución. Eran nombrados por el Gobierno, de ternas que el jefe de policía elevaba, según informes de sus subalternos. El Tribunal Superior informaba y los salientes recibían juramento de los entrantes. Cuando las funciones de comisario quedaron anexadas a los jueces de paz, fueron éstos los que estaban a cargo de las ternas y en la ciudad se ordenó en 1847 al jefe de policía que elevara las ternas para la elección de los jueces (Reguera, 2010).

Terminado el gobierno de Juan Manuel de Rosas, la concentración de funciones administrativas a nivel local se mantuvo, dado que el texto constitucional de 1854 que estableció el régimen municipal en todo el Estado- dejaba la elección, atribuciones y deberes a una ley específica. ${ }^{7}$ Esa ley, sancionada el 16 de octubre de 1854, determinaba que en la ciudad el presidente nato de la municipalidad era el ministro de gobierno y en la campaña el presidente de la municipalidad de cada partido era el juez de paz. En ambos casos, se transformó en el único conducto de comunicación con las autoridades, con los otros jueces de paz y con los jefes militares. Junto con cuatro vecinos propietarios, quedaba encargado del régimen económico y administrativo de su distrito En la campaña el juez de paz era nombrado por el Gobierno a propuesta en terna de la Municipalidad, pero pocos años después no debía sujetarse a estas ternas (ROGBA, 1854; 107-117)

En cuanto a las funciones judiciales, el cambio más importante fue la instalación de la primera instancia en la campaña dividida en dos Departamentos (Norte y Sud), por ley del 29 de noviembre de 1853. Eran juzgados criminales que podían atender causas civiles a pedido de las partes, agregándose en 1856 el Departamento del Centro. (Corva, 2005) Paralelamente se modificó la jurisdicción contenciosa de los juzgados de paz en la ciudad y la campaña, extendiendo su conocimiento y decisión a toda cuestión que no excediera los cuatro mil pesos moneda corriente, exceptuando toda causa surgida por inventarios o tasaciones testamentarias, que pasaba a los juzgados de primera instancia. ${ }^{8}$

6 Se refiere al ejercicio de la policía judiciaria, en lugar de los comisarios suprimidos, que debían combatir la vagancia, y a los procesos sumarios y verbales en los casos de uso de cuchillo, heridas leves, hurtos simples, palabras obscenas o insultos y el robo de ganado hasta seis cabezas.

7 Registro Oficial del Gobierno de Buenos Aires (en adelante ROGBA), 1854, Buenos Aires, Imprenta de "El Orden", 1856, pp.45-46.

8 Ley del 19 de septiembre de 1854. ROGBA, 1854, pp. 97-98. Tenía un antecedente en una breve ley del 16 de septiembre de 1853 y determinaba que era competencia del juez de paz las cuestiones de daños y perjuicios rurales hasta ocho mil pesos, las demandas reconvencionales y de la excepción de compensación, arrendamientos y desalojos con un alquiler urbano de mil quinientos pesos y un arrendamiento rural de quinientos, reparaciones y mejoras, asuntos de comercio hasta cuatro mil pesos, injurias verbales o difamaciones de palabra o por escrito, no 
Como estos funcionarios continuaban siendo legos, por pedido del Gobierno Carlos Tejedor redactó un manual en 1861, para servir de guía a los jueces de paz de campaña en el desempeño de la jurisdicción criminal de su competencia y en la ejecución de las diligencias que les encargaban los juzgados de primera instancia del crimen (Tejedor, 1861) Luego se le encargó otro manual para las funciones civiles y administrativas de los jueces de paz que eran comunes a los de la ciudad y la campaña. En la resolución de los conflictos de su competencia debía ser amigable y conciliatorio; cuando cumplía las órdenes de un tribunal superior debía atenerse a su fiel ejecución (Tejedor, 1861).Estos manuales fueron parte de la "transposición didáctica" entre el universo académico y la sociedad civil, representada en estos jueces legos. Su cultura jurídica -como noción de derecho- y judicial -como saber hacer en caso de procedimiento judicial- se fue conformando en el ejercicio del cargo por diversas vías: la lectura didáctica que el Estado ponía a su alcance y la formación práctica y casuística surgida del ejercicio del cargo (Di Gresia, 2007).

En 1857 los jueces de paz fueron separados de todas las funciones policiales al ser creadas en la campaña veinticinco comisarías, que exceptuaban a Junín, Bahía Blanca y Patagones. Este cambio surgió de la experiencia de dividir la provincia en ocho departamentos a cargo de prefectos, para descentralizar los servicios públicos y administrativos (Díaz, 1959). La partida de once hombres asignada a los juzgados quedaba reducida a cuatro y las comisarías eran dotadas con partidas de diez a quince hombres. En noviembre de 1859 se suprimieron prefecturas y comisarías, retornando las funciones a los jueces de paz. La concentración de atribuciones y el control que el juez de paz tenía sobre su partido, sumado al papel de nexo entre éste y el poder central, no pudieron ser modificados.

Dada esta situación, la preocupación por la descentralización había comenzado antes de 1873, con intentos de lograr la división de poderes a nivel local, asegurando una justicia cercana y accesible. El juez de paz debía convertirse en la base del sistema judicial provincial y para ello era indispensable quitarle las funciones de gobierno, creando un poder municipal a cargo de las jurisdicciones locales. Es decir, para que el proceso de descentralización planificado por la Constitución provincial de 1873 fuera posible, era fundamental convertir a los jueces de paz en funcionarios exclusivamente judiciales, pero lo más importante era quitarles la dependencia política central a través de la elección. El objetivo era, al menos en teoría, funcionarios judiciales, elegidos por los vecinos.

La nueva Constitución puso las bases para este cambio en la organización de la Justicia de Paz. Los jueces de paz eran funcionarios exclusivamente judiciales y agentes de los Tribunales de Justicia, que para ser electos debían ser ciudadanos mayores de 25 años, contribuyentes, con dos años de residencia en el lugar donde fueran a desempeñar sus funciones, sabiendo leer y escribir. La elección era

siendo por prensa. Toda causa resuelta por el juez de paz hasta trescientos pesos era inapelable. Otra ley incluyó el conocimiento en contratos de inmigrantes. El monto que fijaba la jurisdicción en lo civil y comercial fue elevado a veinte mil pesos en 1863. 
directa, por electores calificados, esto es mayores de 22 años con residencia de un año. El procedimiento era verbal y actuado y los recursos atendidos por los Tribunales de vecindario, organizados por la ley en la materia, de forma que las causas quedaran terminadas dentro del mismo distrito. En la decisión constitucional no hubo diferencias, pero para concretar la elección directa debía la Legislatura dictar la ley orgánica de la Justicia de Paz. Pero de no sancionarse ese año, el Poder Ejecutivo seguía encargado de nombrar los funcionarios para 1874. Ésta fue la piedra del escándalo. ${ }^{9}$

\section{La decisión de la elección popular}

Reunida la Convención Constituyente, el dictamen de la Comisión encargada del proyecto Poder Judicial fue presentado en la sexta sesión del 15 de junio de 1871. ${ }^{10}$ En líneas generales, proponía un poder independiente que incorporaba el juicio por jurados pero que no decía una palabra sobre la Justicia de Paz, siendo los seis artículos que la conformaron el resultado del despacho de la última Comisión del Poder Judicial compuesta por Ezequiel E. Pereyra, José M. Moreno, Vicente F. López, Francisco Alcobendas, Antonio E. Malaver, Luis Sáenz Peña, Dardo Rocha, Pedro Goyena y Miguel Navarro Viola.

Podemos suponer que la descentralización administrativa se daba por establecida en el proyecto del poder municipal, que dividía el territorio del Estado en distritos a cargo de Cabildos, con miembros elegidos por dos años, pública y directamente por el pueblo, encargados de las funciones que antes desempeñaban los jueces de paz. ${ }^{11}$ Había una especie de acuerdo tácito en que esos jueces de paz, ya sin funciones administrativas, serían funcionarios judiciales y esto quedó reflejado en la votación, pues el artículo referido a las condiciones del juez de paz tuvo sólo dos votos en contra y la elección directa, uno. ${ }^{12}$

La discusión que no se dio en la Convención, decantó en la Legislatura cuando llegó la hora de debatir la ley orgánica de Justicia de Paz. Como hemos visto, la Constitución de la Provincia de 1873 estableció que la Justicia de Paz debía ser ejercida por funcionarios elegidos por el pueblo, cuya única función fuera administrar justicia. En los debates legislativos, ya resuelta en teoría la descentralización, el tema a tratar era la elección de los jueces. El senador Rafael

9 Constitución de la provincia de Buenos Aires de 1873, artículos 178-183 y Disposición transitoria artículo 227. (Corbetta, 1984: 115; 128-129). (En adelante Constitución provincial, 1873) El artículo que disponía la elección directa de los jueces de paz era el artículo 180, pero por el artículo 227, en el resto de ese año y mientras no estuviera dictada la ley orgánica, el Poder Ejecutivo seguía nombrando a esos funcionarios. Agreguemos aquí que este artículo incluía la salvedad también de que seguía funcionando la justicia correccional como hasta el momento, a cago de los jueces de paz en la campaña, pues en la ciudad la ejercía un juez letrado desde 1857.

10 Sesión del 15 de junio de 1871, DCC, pp.100-102.

11 El término Cabildo fue luego reemplazado por el de Municipalidad.

12 Sesión del 27 de junio de 1873, DCC, pp. 1223-1224. 
Ruiz de los Llanos, como miembro informante, llamaba la atención sobre la gran innovación constitucional de crear una justicia verdaderamente popular, una justicia que tuviera su origen en la elección del pueblo, procurando facilidad y eficacia a sus propósitos. Explicaba que la Comisión no había hecho más que reglamentar la creación de la Constitución, utilizando como guía un proyecto bastante bien meditado y estudiado, propuesto en 1872 por el ministro Amancio Alcorta. En el Senado se debatió sobre el sueldo, la duración en el cargo y la reelección de los jueces de paz, pero la elección popular parecía aceptada. ${ }^{13}$

En cambio entre los diputados quedó de manifiesto el enfrentamiento que generaba esta cuestión. Para la Comisión encargada de redactar el proyecto, la elección popular era inconveniente, dada la imposibilidad de uniformar la opinión sobre las personas a las que se les daba el voto en las localidades, pues según sostenía Carlos Marenco, "los que han elegido al juez de paz, esperan favor de él, y los que lo han combatido, no esperarán justicia”. Pero para Luis Sáenz Peña, el Poder Ejecutivo intentaba mantener con el nombramiento una de las prerrogativas constitucionales que la reforma le había arrebatado, la del poder omnímodo que ejercía sobre el juez de paz, representante de la acción oficial en todos los actos administrativos. ${ }^{14}$

En esta misma línea, Luis Vicente Varela explicaba que lo que había tenido hasta entonces la provincia con el nombre de jueces de paz, era una especie de monstruos de poderes absolutos y facultades omnímodas que representaban todos los poderes a la vez. La Convención Constituyente, apercibida del papel político que desempeñaban estos jueces, quiso crear la verdadera institución para que no se continuara con esos funcionarios que se llamaban jueces de paz y no eran otra cosa que "mandones absolutos y caudillos electorales". ${ }^{15}$

La elección popular aseguraba, según estos legisladores, la limitación al Poder Ejecutivo y el fin de los caudillos electorales. Es decir que, para quienes estaban a favor de la elección popular, quitarle al gobernador el nombramiento de los jueces de paz daría por resultado funcionarios judiciales, que no sirvieran a los intereses políticos, sino a los pobladores de su partido. Pero esto entrañaba el riesgo - según advertía Marenco - de generar adhesiones y enfrentamientos a nivel local, que restringian la libertad del voto.

La ley que organizaba la Justicia de Paz, acorde al texto constitucional, fue finalmente sancionada por la Legislatura el 20 de junio de 1877, pero el gobernador Carlos Casares la devolvió con observaciones. ${ }^{16}$ Lo mismo sucedió con

13 Sesión del 8 de julio de 1876, Diario de Sesiones de la Cámara de Senadores, 1876, pp. 142 258. (en adelante DSCS)

14 Sesión del 12 de marzo de 1877, Diario de sesiones de la Cámara de Diputados, 1876, pp. 1586-1627. (en adelante DSCD)

15 Sesión del 14 de mayo de 1877, DSCD, 1877, pp. 93-110.

16 El artículo 105 de la Constitución provincial definía el veto: "El Poder Ejecutivo deberá promulgar los proyectos de ley sancionados, en los diez días de haberle sido remitidos por la Legislatura, pero podrá devolverlos con observaciones durante dicho plazo, y si una vez 
una ley sancionada el 12 de marzo de 1878, por la cual la Legislatura resolvía que mientras se pusiera en práctica la ley de Justicia de Paz con arreglo a la Constitución, los jueces de paz de la ciudad y de la campaña fueran nombrados por el Pode Ejecutivo a propuesta en terna de la Cámara de Diputados.

Retirado el veto de la ley Orgánica de Justicia de Paz por Carlos Tejedor, el Senado se reunió en sesión del 18 de mayo de 1878, haciendo moción Ruiz de los Llanos para que se devolviera al Poder Ejecutivo el original auténtico de dicha ley, que finalmente fue aprobado. ${ }^{17}$ Promulgada el 23 de mayo de 1878, determinaba que cada parroquia de la capital y cada partido de la campaña conformaba un juzgado de paz, con un juez que electo directamente duraba un año en sus funciones. Debían ser ciudadanos mayores de 25 años, contribuyentes, que supieran leer y escribir, con residencia de dos años en la jurisdicción. Los electores calificados eran ciudadanos mayores de 25 años, con un año de residencia, de los que los consejos parroquiales y municipales formaban un padrón especial, siendo también los encargados de la aprobación o anulación de las elecciones que se realizaban igual que las elecciones municipales. ${ }^{18}$

Entre tanto, el 16 de mayo de 1878, el Ejecutivo convocó a elecciones de municipales para el 15 de septiembre, "no siendo conveniente demorar por más tiempo el cumplimiento de la ley orgánica del régimen municipal”, dependiendo de ello "la organización definitiva de la provincia". Por otro decreto del mismo día

transcurrido no ha hecho la promulgación ni los ha devuelto con sus objeciones, serán ley de la Provincia, debiendo promulgarse en el día por el Poder Ejecutivo". En la doctrina norteamericana, tomada como referente en los debates porteños, la simple separación de poderes no era suficiente y el control pasivo del cuerpo legislativo no bastaba, se requería de un control activo: el poder del veto del Ejecutivo y la capacidad de los tribunales de revocar leyes. (Vile, 2007: 177-178) Florentino González explicaba que una de las consideraciones tomadas por la Constitución argentina para que las leyes sirvieran a los intereses de la comunidad, era la de poner "en manos del Jefe del departamento ejecutivo el poder de suspender los efectos de la ley acordada por las Cámaras". El veto suspensivo y la posibilidad de insistencia por los dos tercios de los votos en ambas Cámaras, a pesar de ser objeto de controversia y de ser considerado por algunos una facultad peligrosa, era para el autor una barrera en manos de quien, por la naturaleza de su posición, podía apreciar las consecuencias de una ley, y por ser responsable individual ante la opinión no haría uso de esa facultad sino cuando una ley fuera a todas luces inconveniente. (González, 1869: 277-279)

17 J. Ortiz de Rozas había propuesto resolver algunos defectos del texto antes de presentarlo, por ejemplo la facultad otorgada a los alcaldes de imponer penas pecuniarias y corporales. También la ley obligaba a los jueces de paz a asistir todos los días a sus oficinas en el mismo horario que los demás funcionarios de la administración de justicia, cosa que no correspondía desde el momento que se les había quitado el salario contemplado en el proyecto original.

$18 \mathrm{El}$ texto original sancionado en 1877 no se encuentra en el Registro Oficial, por no haberse promulgado en ese momento. Puede consultarse en la Colección completa de leyes del Estado y Provincia de Buenos Aires desde 1854 a 1881, recopiladas, concordadas y anotadas por Federico Ketzelman y Rodolfo F. De Souza, Buenos Aires, Editorial Lex, 1930, tomo VI, pp. 10-34. (En adelante Ketzelman) El texto promulgado se encuentra en el Registro Oficial de la provincia de Buenos Aires, 1878 primer semestre, Buenos Aires, Imprenta del Mercurio, pp.233-253. (en adelante ROPBA, 1878) 
y ateniéndose a la ley de Justicia de Paz sancionada por la Legislatura el 21 de junio de 1877 - cuyo veto había retirado pero que aún no había sido promulgada dispuso que se realizaran las elecciones de jueces de paz y suplente el 15 de septiembre. ${ }^{19}$ Pero unos días antes la Honorable Legislatura suspendió los efectos de las leyes de Municipalidades y de Justicia de Paz. La Cámara de Senadores había mandado un proyecto de reformas de la ley de Justicia de Paz a la Cámara de Diputados, que respondieron con el proyecto de suspenderla. ${ }^{20}$

La decisión de suspender las leyes de Municipalidades y de Justicia de Paz, fue de la mano de la reforma del artículo 200 de la Constitución provincia, por el cual cada una de las catorce parroquias en que estaba dividida la ciudad de Buenos Aires elegiría un Consejo para su gobierno de barrio. Los diputados que promovían la sanción de estas dos leyes, se basaban fundamentalmente en los inconvenientes económicos que la instalación de estos Consejos generaba, insalvables para un tesoro público desvastado. La propuesta era que cada parroquia eligiera dos municipales y dos suplentes, para formar una Municipalidad de la ciudad. En cuanto a las leyes de Municipalidad y Justicia de Paz, la propuesta del Senado generó una larga y ardua discusión de los diputados que, como ya hemos señalado, terminó con la suspensión de las leyes.

Ningún legislador cuestionaba la necesidad de esas leyes, pero un grupo sostenía la necesidad de "depurarlas previamente de los defectos de que indudablemente adolecen”. ${ }^{21} \mathrm{Al}$ problema económico que generaba la organización de los Consejos parroquiales, se sumaba la novedad de la ley de Justicia de Paz, que reducía el papel de los jueces de paz a funcionarios exclusivamente judiciales, quitándoles toda atribución administrativa y dejándoles tareas muy arduas, con cuatro horas de despacho, desvistiendo el puesto de los atractivos que le daban las funciones políticas y administrativas que ejercían hasta entonces, por lo que ningún ciudadano querría ejercer gratuitamente el cargo, haciendo necesario fijarles un sueldo.

Pero estos fundamentos meramente económicos, ocultaban decisiones políticas relacionadas con la organización de la capital provincial y las atribuciones de los jueces de paz de campaña. A esta posición se oponía un grupo de diputados para quienes una ley no podía dejarse sin efecto antes de ser puesta en práctica, pues las parroquias urbanas y los centros de campaña estaban deseando usar de la vida propia, conquista moderna del sistema municipal. Pero finalmente el Senado aprobó la suspensión de las leyes. ${ }^{22}$

Suspendida la organización de los municipios y de la justicia de paz, el diario La Reforma de Chivilcoy en respuesta publicó un artículo el 15 de septiembre titulado

19 ROPBA, 1878 primer semestre, pp. 223-226.

20 Diario de Sesiones de la Cámara de Diputados de la provincia de Buenos Aires, 1878, Imprenta de "El Economista", Buenos Aires, 1878, pp. 1045-1105. (en adelante DSCD, 1878)

21 DSCD, 1878, p. 1048.

22 Diario de Sesiones de la Cámara de Senadores de la provincia de Buenos Aires, 1878, Imprenta "El Nacional", Buenos Aires, 1881, fs. 614-618. 
"Después del atentado", calificando la ley de suspensión de inconstitucional y arbitraria. La Cámara de Diputados, declarando violados sus privilegios por los conceptos injuriosos, ordenó el arresto del director del diario Luis A. Mohr y de los setenta y ocho vecinos que firmaron, solicitando al Poder Ejecutivo su cumplimiento. El gobernador Tejedor le respondió que correspondía a la Cámara su ejecución, poniendo a su disposición al comisario de policía rural residente en Chivilcoy y haciendo cesar a los vecinos firmantes que desempeñaban funciones públicas. Los diputados decretaron violados sus privilegios y mandaron a arrestar al director del diario y a los firmantes detallando sus nombres, pero finalmente fueron puestos en libertad. ${ }^{23}$ Las elecciones de jueces de paz no se realizaron y el nombramiento para ese año generó un conflicto entre poderes que terminó en la Suprema Corte.

\section{La elección de los jueces de paz: un conflicto de Poderes}

Ante el veto de la ley orgánica que había efectuado el gobernador Casares, la Comisión de Legislación de la Cámara de Senadores tomó en consideración las observaciones contenidas en el mensaje con el que el Poder Ejecutivo devolvió el proyecto el 4 de julio de 1877 y redactó otro proyecto sobre la formación del padrón especial de electores de jueces de paz, cuya sanción aconsejaba. ${ }^{24} \mathrm{El}$ objetivo era salvar el problema de la falta de un padrón especial para calificar los electores de jueces de paz, diferentes a los de municipales y elecciones políticas, que según el Ejecutivo les impedía poner el "cúmplase" al proyecto. La propuesta era que el Poder Ejecutivo dispusiera lo necesario para que las municipalidades y comisiones municipales de la ciudad y la campaña conformaran dicho padrón especial según el artículo 180 de la Constitución provincial. ${ }^{25}$

Algunos senadores sostenían que en lugar de sancionar esa ley, que sólo se refería al padrón, debían insistir con el proyecto de ley orgánica según el artículo 107 de la Constitución. ${ }^{26}$ Pero Ruiz explicó que se trataba de dos cosas diferentes,

23 Ley del 4 de septiembre de 1878, ROPBA, 1878 segundo semestre, pp.100-101. ROPBA, 1878 segundo semestre, pp. 134-140; 147.

24 Comisión de Legislación: Manuel Obarrio, Ruiz de los Llanos, Martín Bustos. Diario de Sesiones de la Cámara de Senadores de la provincia de Buenos Aires, 1877, Buenos Aires, Imprenta Rivadavia, 1877, pp. 571-579. (en adelante DSCS, 1877)

25 Art. 180: "Serán electos directamente por electores calificados, y lo son, los ciudadanos mayores de veintidós años, con residencia de uno por lo menos en el distrito en que se verifica la elección". Para ser elector político se requería de los mismos requisitos que para ser diputado: ser ciudadano de 22 años (arts. 64 y 134). Los electores municipales serían los mismos que para elegir Diputados, "estando inscriptos en le Registro Cívico del municipio y además los extranjeros mayores de 22 años domiciliados en él, que paguen impuesto directo, sepan leer y se inscriban en un registro especial que estará a cargo de la Municipalidad" (art. 201, inc. $3^{\circ}$ ). Constitución provincial, 1873.

26 La posibilidad de insistir sobre un proyecto de ley vetado por el Poder Ejecutivo estaba definida en el artículo 107 de la Constitución provincial, según el cual "devuelto un proyecto por el Poder Ejecutivo será reconsiderado primero en la Cámara de su origen, pasando luego á la 
siendo una necesaria para la otra, pues -como aclaró Francisco Uriburu - los jueces de paz no existirían sin la ley orgánica que especificara sus funciones y la ley en discusión era un mecanismo que permitía elegirlos. Si se optaba por la insistencia, debía realizarse sobre el mismo proyecto, sin modificaciones, lo que hacía imposible que se resolviera el tema del padrón observado por el Gobierno.

La idea era, después de promulgada la ley del padrón, proponer la insistencia. Pero ni una cosa ni la otra ocurrió y los legisladores sancionaron otro breve texto según el cual mientras se organizaba la justicia de paz con arreglo al texto constitucional, los jueces de paz serían nombrados por el Poder Ejecutivo, a propuesta en terna de la Cámara de Diputados. ${ }^{27}$ Tres días después, el gobernador Carlos Casares vetó ese texto legislativo, con un mensaje que firmó junto a sus ministros Carlos Pellegrini y Bonifacio Lastra, en el que realizaba observaciones de carácter formal y constitucional.

El 25 de marzo de 1878, la Cámara de Diputados resolvió insistir por dos tercios en la sanción, pasando entonces a Senadores, que destinó el asunto a la Comisión de Negocios Constitucionales. Pero no fue hasta el 3 de junio de 1879 que el Senado determinó la insistencia, ya con Carlos Tejedor en el Gobierno, que lo devolvió con observaciones. ${ }^{28}$ Debido a la minuta con que respondieron las Cámaras, el 22 de agosto de 1879 el gobernador se dirigió al presidente de la Suprema Corte de Justicia para la resolución de la cuestión de competencia que se había suscitado entre la Honorable Legislatura y el Poder Ejecutivo, con motivo de la sanción de la ley estableciendo una forma transitoria para el nombramiento de los jueces de paz.

Comenzó así el expediente que tiene una lógica interna, propia del procedimiento de la causa, que no sigue un orden cronológico y se divide en cuatro partes. En la primera consta el contenido del conflicto: el texto del proyecto, la insistencia de Diputados, el veto de Carlos Tejedor, la respuesta de las Cámaras y la presentación del gobernador ante la Suprema Corte, que solicitó los antecedentes a las Cámaras. En la segunda, la Cámara de Diputados presentó sus debates de la ley y del veto, acompañados de la nota correspondiente; pero los Senadores no respondían, por lo que el Tribunal debió insistir. Siguen entonces los antecedentes de esa Cámara, acompañados de una nota que básicamente ponía

revisora, y si ambas insisten en su sanción por el voto de los dos tercios de sus miembros presentes, el proyecto será ley, y el Ejecutivo se hallará obligado á promulgarlo. En caso contrario no podrá repetirse en las sesiones de aquel año". Constitución provincial, 1873.

27 Ley sancionada el 12 de marzo de 1878. Ketzelman, tomo VI, p. 473. Cabe aclarar que tampoco se encuentra en el Registro Oficial y que en la Colección está equivocada la fecha por 12 de mayo. En el artículo $1^{\circ}$ disponía que mientras se pusiera en práctica la ley de Justicia de Paz, con arreglo a la Constitución, los jueces de paz de la ciudad y campaña serían nombrados por el Poder Ejecutivo a propuesta en terna de la Cámara de Diputados. La ley, por el artículo $2^{\circ}$, empezaría a regir desde la fecha de su promulgación.

28 Terminado el mandato de Carlos Casares, las pujas internas del autonomismo -cuyos disidentes eran los republicanos- y las negociaciones con los nacionalistas dieron forma a la candidatura de Carlos Tejedor junto a José María Moreno. 
en duda la competencia de la Suprema Corte para resolver el asunto planteado por el Ejecutivo. La última parte del expediente es la sentencia del alto Tribunal, en la que definió su competencia y resolvió el conflicto presentado. ${ }^{29}$

Como se trata de un tema muy complejo, con marchas, contramarchas y diversos actores, que cambian aún en un mismo cargo, hemos decidido seguir una secuencia temporal que permita comprender mejor el conflicto y las diversas participaciones, dado que como podremos observar superan la disyuntiva entre nombramiento o elección de los jueces de paz y dejan al descubierto los cambios políticos de estos años.

La ley que inició el conflicto buscaba que, mientras se organizaba la elección popular directa de los jueces de paz, se lograra una elección de segundo grado quitando al Poder Ejecutivo la facultad absoluta de su nombramiento, dando intervención a la Legislatura con una terna propuesta por la Cámara de Diputados. ${ }^{30}$ El proyecto -que se trató sobre tablas y resultó sancionado- se inició por una solicitud de varios senadores de convocar, de acuerdo con el artículo 80 de la Constitución provincial, a la Cámara a sesiones extraordinarias para ocuparse de un proyecto reglamentando la manera de hacerse el nombramiento de los jueces de paz y comandantes militares.

Entre los solicitantes se encontraban Francisco Uriburu, Bernabé Demaría, Roberto Cano, Ángel Blanco, todos senadores republicanos por la Capital, que se habían presentado el 2 de septiembre de 1877 contra los autonomistas conciliados. (Barba, 1982: 36-37) Pero Juan Carlos Lagos, que también ganó en esa lista, se manifestó en contra sosteniendo una postura más radical, pues el texto de la ley era irreconciliable con la disposición de la Constitución, según la cual los jueces de paz, tan ligados a la cuestión política, debían ser nombrados directamente por el pueblo. Pero le respondieron que se trataba de un nombramiento constitucional provisorio. ${ }^{31}$

Puestos así los términos del debate, se fueron profundizando en las diversas instancias del conflicto. Para algunos, si no se resolvía la elección popular, debían seguir nombrándolos el Poder Ejecutivo, pues no era conveniente "dar esta atribución a la Cámara de Diputados, que es donde más se ponen en juego las pasiones del partido". ${ }^{32}$ Para otros, esa Cámara legislativa era la que representaba más directamente al pueblo y debía intervenir en el nombramiento en forma provisoria.

Pero el tema quizá más urgente y difícil de resolver era el reclamo de la insistencia de la ley orgánica, sin la cual el poder seguiría centralizado, pues visto

29 Poder Ejecutivo Provincial con la Honorable Legislatura sobre un conflicto suscitado con motivo de la sanción de una Ley sobre nombramiento de Jueces de Paz. Archivo de la Suprema Corte de Justicia Provincia de Buenos Aires B 1965. (en adelante PE c/ HL)

$30 \mathrm{PE}$ c/ HL, fs. 1-2.

$31 \mathrm{PE} \mathrm{c} / \mathrm{HL}$, fs. $25-33 \mathrm{v}$.

32 Recordemos que esta idea, entonces en palabras de Lagos, ya habían sido expresada veinte años antes por Bartolomé Mitre. 
desde el Gobierno y en palabras de sus ministros, "los jueces de paz son funcionarios exclusivamente administrativos; son los encargados del cumplimiento de las órdenes que del Poder Ejecutivo emanan y dependen directamente de él". Por esto era el gobernador el responsable directo de la conducta del funcionario, responsabilidad que se diluía si participaba la Cámara al nombrarlos, en una intervención legislativa en el centro mismo del Ejecutivo, atentando contra la armonía de las ramas del poder y llevando al desequilibrio. ${ }^{33}$

Con este fundamento, la respuesta de Casares no se hizo esperar y devolvió con observaciones de forma y de fondo la ley sancionada, en uso de la facultad acordada por el artículo 105 de la Constitución. Respecto a las primeras, señalaba que en lugar de atender las observaciones realizadas a la ley orgánica, dictaron en el mismo período otra ley sobre la materia, contraria al artículo 107 de la Constitución sobre insistencia de proyectos legislativos. Tampoco era válida la disposición de hacer entrar en vigencia la ley desde la fecha de su promulgación, por haber sido sancionada en sesiones extraordinarias. Pero lo más grave era que atacaba el principio fundamental de la división de poderes, violando las facultades equitativas, extralimitando sus funciones al atribuirse una exclusiva del Poder Ejecutivo, queriendo participar del nombramiento de funcionarios administrativos, que aún no eran exclusivamente judiciales. ${ }^{34}$

La Cámara de Diputados insistió el mismo día, por el voto de dos tercios de sus miembros, pero en Senadores fue tratado al año siguiente, decidiendo también insistir en la sanción por dos tercios de la Cámara. De las discusiones - que giran en torno a las mismas cuestiones relacionadas con el gobierno local, pero en las que surgen los conflictos políticos de 1879 - son destacables los argumentos de Demaría, el senador republicano que había iniciado el proyecto y ahora dudaba de su constitucionalidad. De todas formas se veía en la obligación de "quitar de manos del PE armas electorales de que públicamente ha dicho se va a valer, para perseguir un propósito que se propone, es decir su propia candidatura". ${ }^{35}$

Surgía con claridad en la sala el conflicto político que generaba la candidatura presidencial del gobernador de la provincia y el enfrentamiento entre el nombramiento de funcionarios administrativos por decreto y la elección popular de funcionarios exclusivamente judiciales. La ley en discusión proponía entonces, en contra del poder central, una solución intermedia y provisoria, que al dar al cuerpo deliberante parte en el nombramiento de los jueces, daba vida a la "raíz de soberanía popular” de la administración de justicia, que en ese momento era

33 Participación en los debates de los ministros de gobierno, Carlos Pellegrini y de hacienda, Bonifacio Lastra. PE c/ HL, fs. 25-33 v. DSCS, 1878, 1408-1413.

34 Nota devuelta a las Honorables Cámaras con las observaciones acordadas, 15 de marzo de 1878. Firma el gobernador Carlos Casares y sus ministros, PE c/ HL, f. 2 v.

35 PE c/ HL, fs. 34-42. Sesión del 3 de junio de 1879. Diario de Sesiones de la Cámara de Senadores de la provincia de Buenos Aires, 1879, Imprenta de "El Economista", Buenos Aires, 1879, fs. 154-157. (en adelante DSCS, 1879) 
"humilde y considerado instrumento al servicio de los intereses políticos". ${ }^{36}$ Pero lo interesante es que la alternativa provisoria propuesta tenía simultáneamente en contra a quienes sostenían el nombramiento por el Gobierno y a los defensores de la elección popular.

Habiendo resuelto insistir ambas Cámaras sobre la participación de Diputados en el nombramiento de los jueces de paz, le fue comunicado al gobernador Tejedor que respondió con una extensa nota, partiendo de la base de que no podría dar cumplimiento al proyecto "sin faltar a sus sagrados deberes". ${ }^{37}$ También observaba formas irregulares y "en abierta contradicción con las reglas establecidas por la Constitución” para los casos de leyes vetadas con observaciones por el Ejecutivo. La institución del veto del poder colegislador sólo tenía un efecto suspensivo, con el objeto de provocar una nueva demostración de opinión, exigiendo para ello un mayor número de adhesiones, y si al Ejecutivo no le era permitido manifestarse fuera de un término fijo, tampoco podía serle a una de las Cámaras. La ley que no se prestaba a ser vetada por haber cerrado las sesiones, no se promulgaría jamás y necesitaría pasar por los trámites de una nueva sanción pues la renovación del personal de los cuerpos legislativos podía implicar una alteración completa de las opiniones.

Insistía en su carácter de jefe de la administración, que debía nombrar a sus empleados, que se encontraban bajo su responsabilidad y vigilancia. Ningún poder podía modificar el equilibrio de los poderes públicos que la Constitución consagraba para conservar ese equilibrio e impedir la perturbación en "su juego regular y armónico”. Sin rodeos decía a las Cámaras que si pudieran inmiscuirse "en todos los resortes de la administración, el equilibrio de los Poderes habría desaparecido", convirtiendo el régimen constitucional en el despotismo. Si los jueces de paz eran empleados administrativos y judiciales, se había previsto la situación de su nombramiento en su doble carácter: en el primero, dejándolo al Poder Ejecutivo como cualquier otro empleado de la administración, y en el segundo estableciendo la elección directa del Pueblo. ${ }^{38}$ Incluso, si la ley orgánica no se dictaba, la carta constitucional lo preveía en sus disposiciones transitorias, que no podían alterarse. Si lo que querían era que el Gobierno no siguiera nombrando a los jueces de paz como funcionarios judiciales, estaba en sus manos lograrlo sancionando la ley correspondiente.

36 En los debates, el senador Federico de la Barra recordó que las facultades del juez de paz no eran sólo administrativas sino también judiciales, y era de forma y de esencia que el poder deliberante tomara parte en el nombramiento y autorización de los jueces, sumado a la raíz de soberanía popular que llevaba la administración de justicia de los jueces. En todo el mundo era la base más poderosa de la administración de justicia, y aquí llegaría a ser un magisterio augusto, hoy humilde y considerado instrumento al servicio de los intereses políticos. DSCS, 1879.

379 de junio de 1879, PE c/ HL, fs. 4-10 v.

38 Sancionada la Constitución, los jueces de paz seguían siendo para el Poder Ejecutivo empleados de policía y para el Poder Legislativo eran empleados exclusivamente judiciales que, mientras no existiera la ley que regulara la elección popular, debían ser elegidos como los otros magistrados. 
Estas observaciones de Tejedor demandaban una respuesta y a eso se dedicaron los diputados en una sesión en la que se trató por primera vez la propuesta de llevar el conflicto ante la Suprema Corte. Dada la gravedad de las cuestiones constitucionales en juego y el enfrentamiento político que se había generado, Héctor Varela definió la situación como una batalla que "había que darla cuanto antes". 39

En la discusión, una cuestión fundamental fue la utilidad del veto, presentada por José María Cantilo, que insistía en quitar a uno y otro poder lo que hiciera peligrar las instituciones y la paz pública. En su exposición aseguraba que la gran conquista norteamericana era haber alcanzado el equilibrio del sistema gubernativo - para lo que el veto era indispensable - y afirmaba que "el día que se consiga entre nosotros establecer este equilibrio perfecto, de manera que el PE gire en su órbita con el PL, sin chocarse y sin querer arrebatarse atribuciones uno al otro, entonces podremos haber dicho [...]: hemos llegado a los altos fines que se han buscado con el orden constitucional establecido".

Para dar mayor consistencia intelectual a su argumento recurrió a Joseph Story, ${ }^{40}$ que justificaba la necesidad del veto en la tendencia natural del Poder Legislativo a mezclarse con los derechos de los otros poderes y a absorber sus atribuciones, definiéndolo como un recurso más contra el establecimiento de leyes inconsideradas, prematuras o impropias, como lo era para Cantilo la que había sido devuelta por Tejedor. A diferencia del veto inglés, era un arma que permitía escuchar las objeciones del Ejecutivo, demorando la sanción de una ley, pero respetando la voluntad de la rama legislativa, que tenía la posibilidad de manifestarse por los dos tercios de los miembros de cada Cámara. Sin embargo, la facultad del veto era ilusoria si se esperaba la renovación de una Cámara para obtener esos dos tercios. ${ }^{41}$

Frente a este discurso estaban quienes, como Rafael Hernández, insistían en la urgencia de terminar de alguna forma con los "señores de horca y cuchillo", resolviendo el nombramiento de los jueces de paz con la reforma del mecanismo administrativo. Esto permitía al vecindario de cada partido elegir su juez de paz "que dirimiera las cuestiones civiles", su comandante "que debía organizar la guardia nacional", su maestro de escuela "que debía educar a sus hijos" y hasta su cura "que había de dirigir sus familia". Una vez establecido el principio

39 Sesión del 18 de junio de 1879, Diario de sesiones de la Cámara de Diputados, 1879, pp. 311-331. Consideración de la Comisión de Negocios Constitucionales en el Mensaje del PE devolviendo con observaciones el proyecto de ley sobre nombramiento de los Jueces de Paz (Se aprueba), PE c/ HL, fs. 13-23. Se inició el debate con la lectura de la nota de Tejedor y del dictamen de la Comisión de Legislación que consideraba "la ley perfectamente cumplida con arreglo a nuestras prescripciones constitucionales", sin desvirtuar la forma de las instituciones y subvertir los principios de Gobierno. Volviendo sobre dicho asunto y tomando en consideración las observaciones contenidas en su mensaje resolvieron que se volviera al PE a los efectos del art. 107 de la Constitución. L. V- López-L.N. Alem- Vicente Villamayor-Salvador J. Socas- Félix R. Pizarro

40 Joseph Story (1779-1845) abogado y escritor jurídico norteamericano, autor del Comentario sobre el conflicto de las leyes, publicado en 1834 y traducido por Clodomiro Quiroga.

$41 \mathrm{PE} \mathrm{c} / \mathrm{HL}$, fs. $18-18 \mathrm{v}$. 
constitucional por el cual la elección del juez de paz correspondía al pueblo, estaban entre los dos poderes disputando una facultad que no pertenecía a ninguno, estaban "peleando por una cosa ajena". En esta línea, pero en términos más contundentes, Estanislao Zeballos declaraba que si el Poder Ejecutivo continuaba con el arma de la elección de las municipalidades y los jueces de paz, ambas instituciones quedarían desnaturalizadas, dejando de ser una institución para el gobierno propio y pasando a convertirse en una institución para el gobierno del partido dueño de este resorte. ${ }^{42}$

Cuando la minuta de comunicación fue tratada por los senadores, en una discusión extensa y ríspida, el núcleo fue la modificación de la última frase. En el texto original se devolvía el proyecto al Ejecutivo "a los efectos del artículo 107 de la Constitución", pero parte de la Comisión de Legislación en mayoría proponía cambiarla por "a los fines consiguientes", considerando que era una fórmula que importaba mayor consideración y respeto entre los poderes públicos. En realidad, cada frase representaba una postura en relación al papel que el Poder Ejecutivo debía jugar. Si se adoptaba la propuesta de los diputados, la ley debía ser inmediatamente promulgada; si se elegía la nueva sugerencia de los senadores, se dejaba al gobernador la puerta abierta para llevar el conflicto ante la Suprema Corte.

En el contexto de estas discusiones surgió la Suprema Corte como posible solución al conflicto, pues para algunos senadores la Legislatura no podía obligar al Poder Ejecutivo a promulgar una ley. Cuando se generaba un conflicto de poderes, la Constitución había contemplado que un Tribunal lo resolviese, y "a los fines consiguientes", significaba que el gobernador recurriera a la Suprema Corte. ${ }^{43}$ Esto generó la reacción de Bernardo Solveyra, para quien esa frase equivalía a reconocer que "tiró el diablo de la manta y se descubrió el pastel", es decir, que lo que la mayoría de la Comisión quería era que se hiciera del conflicto una cuestión de competencia frente a la Corte, para preguntarle si el Poder Legislativo tenía derecho a sancionar leyes. Pero según su entender, no era cuestión de competencia, pues el Gobierno no podía vetar una ley dos veces, y si la Legislatura insistía por dos tercios, esa disposición era ley. Si esa ley era inconstitucional iría al Tribunal Superior cuando dañara a un particular, según la doctrina de todo el mundo, de la Constitución Nacional y de las constituciones de los estados federales de Norteamérica. ${ }^{44}$

Aprobada la minuta original, se presentó al Ejecutivo firmada por los presidentes y secretarios de ambas Cámaras, sosteniendo que la ley era "perfectamente cumplida con arreglo a nuestras prescripciones constitucionales", sin desvirtuar la forma de las instituciones y subvertir los principios de Gobierno, por lo que habían resuelto que se volviera al PE a los efectos del artículo 107 de la

$42 \mathrm{PE} \mathrm{c} / \mathrm{HL}$, fs. $19-20 \mathrm{v}$.

43 Montes de Oca, miembro disidente de la comisión.

$44 \mathrm{PE}$ c/ HL, fs. 43-51. Sesión del 25 de julio de 1879. DSCS, 1879, fs. 477-493. 
Constitución. ${ }^{45}$ Pero casi un mes después, Carlos Tejedor resolvió "someter los antecedentes necesarios para la resolución de la cuestión de competencia que se había suscitado entre la Honorable Legislatura y el PE con motivo de la sanción de la Ley estableciendo una forma transitoria para el nombramiento de los jueces de paz" al presidente de la Suprema Corte de Justicia. Había resistido el cumplimiento de esa ley por considerarla inconstitucional y recurría a la Corte para que tuviera a bien dar solución al conflicto entre ambos poderes, en virtud de las atribuciones que le confería el inc. $2^{\circ}$ del artículo 156 de la Constitución. ${ }^{46}$

Es decir que de todas formas el gobernador recurrió a la Corte, y ésta libró oficio a la Honorable Legislatura de la provincia pidiéndole se sirviera remitir la discusión y antecedentes relativos al asunto. ${ }^{47}$ Además de los documentos anualizados enviados por las Cámaras, es fundamental tener en cuenta sus respuestas. La Cámara de Diputados respondió pocos días después aclarando que el envío de los antecedentes no implicaba modificar el juicio que tenía sobre la competencia absoluta del Poder Legislativo en el asunto. La Cámara de Senadores requirió de la insistencia de la Suprema Corte, para el 3 de diciembre de 1879 presentar una nota declarando que no podían reconocer la competencia del Tribunal.

Para los Senadores, la ley en cuestión había pasado por todos los mecanismos constitucionales y el Poder Ejecutivo debía promulgarla. En los argumentos expuestos sobre la competencia de la Suprema Corte se estaba jugando la definición del papel que ésta jugaba en la división de poderes. Para los legisladores, permitir a las Cortes provinciales intervenir en los conflictos entre poderes sería privarles del desempeño de sus deberes, pues bastaba moverles un pleito y esperar por un año la resolución. Cada uno de los poderes establecidos por la Constitución era el juez de sus atribuciones, siendo poderes independientes y coordinados. Las leyes sólo podían ser revisadas por el Poder Judicial cuando lesionaban derechos o intereses individuales, las causas de competencia eran casos particulares y la Cámara no podía aceptar un litigio formado entre los dos poderes ante la Suprema Corte. Por respeto, habían acordado remitir los antecedentes solicitados, sin que debiera interpretarse como reconocimiento de competencia y esperando que la Suprema Corte declarara su incompetencia. ${ }^{48}$

4525 de julio de 1879, PE c/ HL, fs. 11-11 v.

4622 de agosto de 1879, PE c/ HL, fs. $12-12$ v. Art. 156. La Suprema Corte de Justicia tiene las siguientes atribuciones: [...] $2^{\circ}$ Conoce y resuelve originaria y exclusivamente, en las causas de competencia entre los Tribunales de Justicia con motivo de su jurisdicción respectiva.

472 de septiembre de 1879, PE c/ HL, f.12 v.

$48 \mathrm{PE} \mathrm{c} / \mathrm{HL}$, fs. 52-54. 


\section{La sentencia de la Suprema Corte}

El 24 de enero de 1880 la Suprema Corte firmó la sentencia que, como era de esperar, dedicaba la primera parte a establecer su competencia, para luego responder a la demanda. Los magistrados comenzaron por definir la relación entre la nación y las provincias en el sistema de gobierno elegido:

La Nación Argentina, está constituida, por tradición y por voluntad, bajo el régimen representativo, republicano, federal. Tal organización no permite en las soberanías locales, que son las partes que forman el todo para la que se ha dado aquella organización, ni un solo poder absoluto, ni un poder con facultades ilimitadas, por cuanto ello sería la negación de esa misma forma republicana de gobierno, que implica el libre ejercicio de los poderes públicos, que la componen obrando cada uno independientemente, dentro de la órbita de sus atribuciones constitucionales. ${ }^{49}$

Para hacer esto efectivo, los constituyentes de 1853 establecieron "la intervención nacional sin requisición y confiaron al Poder Judicial la atribución de dirimir los conflictos internos, que ocurrieran entre los poderes públicos de cada Provincia”. Cuando en 1860 el texto constitucional fue revisado, la provincia creyó que el propósito de dar mayores seguridades a la forma republicana, había afectado la misma forma federal, menoscabando las autonomías provinciales. Entonces no sólo limitó las atribuciones, exigiendo la requisición, sino que borró la facultad de la Corte Suprema de intervenir en los conflictos internos por considerarla "atentatoria a la soberanía provincial, subvención completa del orden constitucional de cada localidad, dando lugar a mayores conflictos que los que pretende evitar, cuando hay medios fáciles y conocidos, sin salir del círculo de las leyes provinciales para dirimir tales conflictos". En caso de conflicto entre los poderes provinciales, debían atenerse a la Constitución provincial de cada Estado.

Estas ideas "que se convirtieron en mandato para la república" y se hicieron práctica con la reforma de la Constitución provincial respecto al juego del Poder Judicial en esos casos, "obligaban tanto al Poder Ejecutivo de la Provincia, como al Legislativo mismo, a concurrir a la Sala Jurídica que constituía un Consejo Consultivo de Derecho" en todos aquellos casos dudosos y conflictivos administrativos o interprovinciales, cuya solución necesitara ser arreglada a los antecedentes, a las leyes vigentes y a las prácticas inconcusas".

Entonces, por el texto constitucional provincial la Suprema Corte ejercía, conocía y resolvía originariamente y exclusivamente, en las causas de competencia entre los Poderes Públicos de la provincia, y

...causas de competencia no son sino fundamentos de jurisdicción, es decir conflictos nacidos sobre el alcance de las atribuciones constitucionales, en cada uno de los Poderes subordinados al régimen Federal; y son esas causas de competencia, esos conflictos, como los clasificaban nuestros constituyentes, lo que ha sido la Corte llamada a decidir.

49 PE c/ HL, fs. 54 v.- 72. Las siguientes citas corresponden al fallo de la Suprema Corte en el expediente. 
Pero eso no significaba declarar una superioridad del Poder Judicial sobre el Legislativo, y Hamilton lo había expresado con claridad:

Esta conclusión supone en manera alguna superioridad del Poder Judicial sobre el Legislativo. Supone únicamente que el Poder del Pueblo es superior a los dos; y que donde la voluntad de la Legislatura declarada en sus estatutos, está en oposición con la del Pueblo, declarada en la Constitución, los jueces deben dirigirse por ésta, antes que por aquellos, deben reglar sus decisiones por las reglas fundamentales, antes que por aquellas que no lo son.

Siendo el Poder Judicial el más débil respecto a sus medios de acción, procediendo sólo pasivamente, limitándose a emitir su juicio sólo cuando le era requerido, sería siempre el menos peligroso para los derechos políticos de la Constitución, por ser el menos capaz de dañarlos u ofenderlos. Por todo esto la Corte se declaraba competente y pasaba a tratar la cuestión de fondo: la constitucionalidad o inconstitucionalidad de la ley sancionada por la Legislatura en 12 de marzo de 1878.

Para los jueces de la Suprema Corte, la institución de la Justicia de Paz había sido desnaturalizada especialmente en la campaña, inutilizada con el recargo de atribuciones y deberes muchas veces incompatibles. Eran jueces, municipales, comisarios de policía, agentes del Ejecutivo y de los tribunales. Esto sumado a la forma de elección diferida al gobernador, había hecho que un tribunal fraternal y de concordia, cayera en descrédito y llegara hasta ser perjudicial. Un movimiento poderoso de opinión urgía modificar esa situación, reclamando los vecindarios la elección de los jueces y su función exclusivamente judicial. Entonces, la forma de elección de los jueces de paz directa y popular se había convertido en un precepto explícito de la Constitución, que ninguna ley bajo ningún motivo, ni aunque fuese de carácter provisorio, podía variarlo o alterarlo atacando el texto constitucional y llevando en sí el germen de la nulidad insanable.

La ley fundamental había previsto en el artículo 227 los mecanismos para que la justicia de paz funcionara cuanto antes, encargando a la Legislatura la redacción de la ley orgánica -que no podía demorarse - y entre tanto sancionaba el mantenimiento del orden de cosas, siendo solamente constitucional la elección popular de los jueces de paz. Si se había dejado al Ejecutivo el nombramiento, fue porque en la situación provisoria era natural mantener el status quo, teniendo en consideración que los jueces de paz en las múltiples funciones que conservaban era empleados administrativos y de carácter ejecutivo, debiendo esto desaparecer por el esfuerzo ilustrado y patriótico de los legisladores.

El artículo 42 de la Constitución tampoco podía utilizarse como argumento, porque estaba expresamente estipulada la forma de elección de los jueces de paz y no podía reemplazarse por otra. ${ }^{50}$ Entre tanto el Ejecutivo debía nombrarlos y, como afirmaba Madison, "el ejercicio separado y distinto de los diferentes Poderes

50 "Artículo 42: Los empleados públicos, a cuya elección o nombramiento no provea esta Constitución, serán nombrados o elegidos según lo disponga la ley”. Constitución provincial, 1873. 
del gobierno, es esencial para la conservación de la libertad". Por todo esto, la Suprema Corte resolvía que la ley del 12 de marzo de 1878 no entraba en las atribuciones de la Legislatura por ser inconciliable con los artículos 180 y 227 de la Constitución y mandaba comunicar por oficio con testimonio a la Honorable Legislatura y al Poder Ejecutivo. ${ }^{51}$

En una circular impresa, dirigida el 31 de enero de 1880 a todos los juzgados de paz, el gobernador Carlos Tejedor a través de su ministro de gobierno Santiago Alcorta, informó sobre el conflicto y su resolución. Explicaba que en junio la Legislatura envió al Poder Ejecutivo una ley para su promulgación, por la cual se establecía que mientras no se pusiesen en vigencia las leyes Orgánicas de Municipalidades y de Justicia de Paz, "el nombramiento de los Jueces de Paz, sería hecho por el Poder Ejecutivo de ternas que le presentaría la Cámara de Diputados". Esta ley, vetada por la anterior administración, era devuelta con insistencia, más de un año después. Pero el gobernador se resistía, manifestando en nota a las Cámaras que no se habían observado las formas requeridas por la Constitución, en la insistencia al veto del PE, y que las disposiciones de la ley "importaban una violación a la carta fundamental". Las Cámaras insistieron con la promulgación de la ley y el Poder Ejecutivo sometió el caso a la Suprema Corte, "para que resolviese el conflicto entre los dos Poderes, en virtud a las atribuciones que le confiere el inciso $2^{\circ}$ del Artículo 156 de la Constitución”. La Suprema Corte dio su fallo declarando la ley inconstitucional. ${ }^{52}$

\section{Conclusión}

Partiendo de la preocupación por saber quiénes y cómo elegían y nombraban a los jueces de paz, nos encontramos con un conflicto que no solamente se centraba

51 Jueces de la Suprema Corte: Sixto Villegas, Manuel Escalada, Alejo B. González, Sabiniano Kier, Víctor Martínez. En la sesión del 3 de septiembre de 1878 esta Suprema Corte había presentado el proyecto de Organización de los Tribunales y su jurisdicción. Se imprimió, repartió y se pasó a la Comisión de Legislación, fechada el 31 de agosto. Sobre la Justicia de Paz decía que la ley del 23 de mayo del año corriente había realizado el pensamiento consignado en los artículos 178 a 183 de la Constitución. Esta justicia popular y de índole paternal, respondía a una aspiración bien definida de los habitantes de la provincia. Libre de las reglas que encadenaban a los Tribunales letrados daría solución definitiva a esa multitud de negocios de menor cuantía cuyos capitales había absorbido en gran parte por las costas que en la actualidad soportaban. Merced a esta institución, el habitante de "nuestras dilatadas campañas", encontraría la Justicia en su propio domicilio, no estando obligado a buscarla a largas distancias y con grandes dispendios. La Corte tenía preparada algunas reformas y modificaciones a la ley sancionada pero se había detenido ante la idea de que obstarían a su inmediata ejecución y creyendo que sería más acertado una vez que la institución funcionara, corregir los defectos o suplir las deficiencias que la experiencia señalara, por medio de las leyes complementarias. En los primeros ensayos de la Justicia de Paz, con la extensión de las atribuciones que se le había dado, habría muchos inconvenientes, pero como decía la Comisión de la Cámara de Diputados en el año 1872, al presentar un Proyecto sobre la organización de los tribunales "es de esperarse que la educación, el progreso de la ideas, el adelanto en el camino de las instituciones de los países libres, y el convencimiento de la bondad del principio del gobierno propio influyan pronta y eficazmente en el espíritu de todos y hagan conocer las ventajas del sistema”. DSCS, 1878, fs. 596-615.

52 Notas del juzgado de paz de Exaltación de la Cruz, año 1880, f. 18. "Nombramiento de los jueces de paz. Sobre insistencia del veto a las leyes de municipalidad y justicia de paz del PE". 
en la problemática de la justicia de paz y la concentración de atribuciones, sino que reflejaba la necesidad de definir qué significaba el sistema republicano y qué papel jugaba cada uno de los poderes en él. En la teoría, el sistema de frenos y contrapesos requería de la elección popular frecuente de los funcionarios, y si bien en un principio la idea era que la provincia de Buenos Aires eligiera en forma directa a sus magistrados, el texto constitucional determinó que los jueces legos, no los letrados, fueran elegidos por el pueblo.

Pero llevar a la práctica el artículo constitucional respectivo no resultó tan sencillo y la ley que inició el conflicto buscaba que, mientras se lograba la elección popular de los jueces de paz, se quitara al Poder Ejecutivo la facultad absoluta de su nombramiento, dando intervención a la Legislatura con una terna propuesta por la Cámara de Diputados. Ante la posibilidad de este cambio, el gobernador se declaró responsable directo de la conducta del funcionario, aunque el juez de paz reuniera en sí atribuciones administrativas y judiciales, asegurando que si querían la elección popular debían legislar el artículo constitucional que declaraba a los jueces locales funcionarios exclusivamente judiciales.

En esta puja entre poderes se pueden ver en acción dos instituciones directamente relacionadas con la búsqueda de su equilibrio. Por un lado el veto del gobernador al poder colegislador, que como Tejedor define tenía sólo un efecto suspensivo, con el objeto de provocar una nueva demostración de opinión, pero que también era "un arma" que permitía escuchar las objeciones del Ejecutivo, demorando la sanción de una ley. La otra era la competencia originaria y exclusiva de la Suprema Corte en las causas de conflicto entre los poderes públicos de la provincia, en las que se constituía en un "Consejo Consultivo de Derecho", en casos conflictivos administrativos o interprovinciales.

Para el Ejecutivo, en ejercicio del veto, la ley tenía trabas de forma y de fondo, pero para la Suprema Corte el problema de la ley no estaba en el mecanismo con que había sido sancionada, sino en que era de por si inconstitucional, pues modificaba un artículo que determinaba la elección directa y popular de los jueces de paz, que "ninguna ley bajo ningún motivo, ni aunque fuese de carácter provisorio, podía variarla o alterarla atacando el texto constitucional y llevando en sí el germen de la nulidad insanable".

En la reacción de los legisladores ante los otros poderes, pueden determinarse tres posturas relacionadas con el Estado que se pretendía definir. En primer lugar los promotores de la ley, que estaban buscando una solución provisoria, en lugar de poner en funcionamiento la ley orgánica de justicia de paz, dándole mayor poder al Legislativo; luego quienes defendían la atribución del Ejecutivo de elegir a los jueces de paz, recurriendo a la Suprema Corte para resolver el conflicto; finalmente quienes sostenían sin discusión la elección directa y popular. Eran posturas de alguna forma irreconciliables, que terminaron con la eliminación de la elección popular.

Quedaba de manifiesto el conflicto político de una provincia que a pesar de haber intentado "conciliar" sus fuerzas políticas, sancionando la Constitución de 1873, y que buscaba organizar la base del sistema judicial, tenía muchas cuestiones 
sin resolver, como por ejemplo la relación entre los poderes y la resolución de sus conflictos. A pesar de todos los intentos previos, el juez de paz se convirtió en funcionario exclusivamente judicial en 1885 y la ley orgánica de justicia de paz fue sancionada en 1887. Pero este juez lego nunca fue elegido por los vecinos, pues por esa ley -confirmada por la reforma constitucional de 1889- era nombrado por el Poder Ejecutivo a propuesta en terna de su respectiva Municipalidad. ${ }^{53}$

53 Capítulo II, artículo 12. Registro Oficial de la provincia de Buenos Aires, Imprenta El Día, 1887, p. 389; Constitución de la provincia de Buenos Aires de 1889, art. 183. En la sesión del 3 de octubre de 1889 de la Convención Constituyente fueron presentadas y aprobadas sin observaciones las reformas al artículo vigente que determinaba la elección directa por electores calificados de los jueces de paz, según las cuales pasaban a ser nombrados por el Poder Ejecutivo a propuesta en terna por las Municipalidades. Debates de la Convención Constituyente, Tomo II, abril de 1888 hasta octubre de 1889, Provincia de Buenos Aires, p. 420. 


\section{Bibliografía}

BARBA, F. (1982). Los autonomistas del 70. Auge y frustración de un movimiento provinciano con vocación nacional, Buenos Aires.

Cansanello, O (2003). De súbditos a ciudadanos, ensayo sobre las libertades en los orígenes republicanos 1810-1852, Imago mundi,, Buenos Aires.

Corbetta, J. C. (1984). Textos constitucionales de Buenos Aires, Buenos Aires, Suprema Corte de Justicia.

Corva, M. A. (2005). "La justicia en la campaña, el rol del juez de paz como sumariante, 1855-1880", en Actas del VIII Congreso de Historia de los Pueblo de la Provincia de Buenos Aires (CD), Luján.

(2005). "La Justicia letrada en la campaña bonaerense", en revista Temas de historia argentina y americana No 7, Julio-Diciembre, 2005, UCA, Facultad de Filosofía y Letras, Instituto de Historia Argentina y Americana.

-2014). Constituir el gobierno, afianzar la justicia. El Poder Judicial de la provincia de Buenos Aires (1853-1881), Prohistoria ediciones- Instituto de Investigaciones de Historia del Derecho, Rosario / Buenos Aires.

DíAz, B. (1959). Juzgados de Paz de Campaña de la Provincia de Buenos Aires (18211854), Facultad de Humanidades y Ciencias de la Educación, Departamento de Historia, UNLP, La Plata.

(2014) "La organización de prefecturas de campaña de Buenos Aires durante el gobierno de Valentín Alsina”, en Trabajos y comunicaciones, núm. 8, UNLP.

Di GRESIA, L. (2007). "Jueces rústicos: saberes legos. Esbozo para un estudio de la formación judicial de los Jueces de Paz en el sudbonaerense (segunda mitad del siglo XIX), en XI Jornadas Interescuelas/ Departamentos de Historia, Tucumán, 19 a 22 de septiembre de 2007.

(2014) "Jueces de paz, masones y conservadores en la campaña bonaerense. Una aproximación a las redes vinculares en el sur de la provincia de Buenos Aires (Tres Arroyos, 1865-1910)”, en Mundo Agrario, vol. 11, núm. 21.

FRADKIN, R. (1999). "La experiencia de la justicia: estado, propietarios y arrendatarios en la campaña bonaerense, 1800-1830", en La Fuente Judicial en la construcción de la memoria, Suprema Corte de Justicia de la provincia de Buenos Aires, Mar del plata. 
(2009) “¿Misión imposible? La fugaz experiencia de los jueces letrados de Primera Instancia en la campaña de Buenos Aires (1822-1824)”, en BARRIERA, Darío G. -compilador- Justicias y Fronteras. Estudios sobre historia de la Justicia en el Río de la Plata, Editum, Murcia.

GaraVAGLiA, J. C. (1999) "Paz, orden y trabajo en la campaña: la justicia rural y los juzgados de paz en Buenos Aires, 1830-1852" en Poder, conflicto y relaciones sociales, El Rio de la Plata, XVIII-XIX, Rosario, Homo Sapiens Ediciones.

(1999) "La justicia rural en Buenos Aires durante la primera mitad del siglo XIX (estructuras, funciones y poderes locales)” en Poder, conflicto y relaciones sociales, El Río de la Plata, XVIII-XIX, Rosario, Homo Sapiens Ediciones.

Construir el estado, inventar la nación. El Río de la Plata, siglos XVIII-XIX, Prometeo Libros, Buenos Aires, 2007.

González, F. (1869). Lecciones de derecho constitucional, Buenos Aires, Imp. Lit. y Fundición de tipos de J.A. Bernheim.

Hras, C. (1925). Carlos, "La supresión del Cabildo de Buenos Aires", en Humanidades núm.20, UNLP, La Plata.

LEVAGGI, A.(1981). "Espíritu del constitucionalismo argentino de la primera mitad del siglo XIX", en Revista de Historia del Derecho, núm.9, Buenos Aires, Instituto de Investigaciones de Historia del Derecho.

Levene, R. (1940). Historia de la provincia de Buenos Aires y formación de sus pueblos, vol. I, La Plata, Talleres de impresiones oficiales.

MANNORI, L. (2007).a "Justicia y administración entre Antiguo y Nuevo régimen”, Revista jurídica, Universidad Autónoma de Madrid, Número 15.

MORELl, F. (2007). "Orígenes y valores del municipalismo iberoamericano", Arucaria, vol. 9, núm. 18, 2007, Universidad de Sevilla, España.

REgUerA, A. (2010). "Construcción y funcionamiento de una red de poder egocentrada. LA correspondencia de Juan Manuel de Rosas con los jueces de paz de la campaña bonaerense (1829-1852), en Mundo Agrario, vol. 11, núm. 21.

RomaY, F. (1950). "Reseña histórica de la policía rural bonaerense”, en Primer Congreso de Historia de los pueblos, Archivo Histórico de la provincia de Buenos Aires.

SÁBATO, H. (2009). "Resistir la imposición”: Revolución, ciudadanía y República en la Argentina de 1880", en Revista de Indias, 2009, vol, LXIX, núm. 246. 
TernaVAsio, M. (1999) "De la ciudad colonial al municipio moderno: la supresión de los Cabildos en el Estado de Buenos Aires", Jornadas EscuelasDepartamentos de Historia, Neuquén.

(2000) "La supresión del Cabildo de Buenos Aires: ¿crónica de una muerte anunciada?, en Boletín del Instituto de Historia Argentina "Dr. Emilio Ravignani" Tercera serie, núm. 21.

VILE, M. J. (2007). Constitucionalismo y separación de poderes, Madrid, Centro de Estudios políticos y constitucionales, 2007, [1967]. 